\title{
Investigation on the Flow Structures in the Tip Region for a Transonic Axial Compressor Rotor
}

\author{
Tianye $\mathrm{Ji}^{1}$, a, Xie Fang ${ }^{1}$, YoujunWang ${ }^{1}$ and Tao $\mathrm{Yi}^{1}$ \\ ${ }^{1}$ Xi'an Research Institute of Hi-tech, Xi'an 710025, Shaanxi, People's Republic of China \\ a15594809968@163.com
}

Keywords: transonic compressor, numerical simulations, tip leakage flow

\begin{abstract}
The effect of flow structures in the tip region on the stability of NASA Rotor 37 has been examined with numerical simulation. Stall inception mechanism of Rotor 37 is presented firstly with principal focus on the tip leakage flow behavior, passage shock wave and leakage flow vortex. Detailed survey reveals three features: (1) there exists an interface between the incoming main flow and the tip leakage flow;(2) in this rotor, the tip leakage flows along the blade chord can be divided into at least three parts, each part plays a different role in the tip region;(3) the combined interaction of the stagnated blockage due to breakdown of the leakage vortex and the leakage flow from the leading edge leads to the tip stall inception. When flow and tip leakage flow intersect with each other, there is great rivalry between the two flows. If the power of incoming flow is relatively large, the flow will be coerced a lot of tip clearance leakage flow smoothly into the passage. And vortex breakdown would not have happened to produce large numbers of low-energy groups. And after the "collision" of the incoming flow, the secondary tip clearance flow will be greatly reduced. The efficiency of compressor will rise. Conversely, if the power of incoming flow is relatively small, tip part of the clearance leakage flow will be enveloped into the blade passage by main flow. But this part is unable to be taken out of the blade passage, and the collision of the two weakens their respective power further more. Under the influence of reverse pressure gradient, the vortex breakdown and low energy mass blockage escalate. As a result of the gradually decreasing power of the incoming flow, the secondary tip clearance flow get emerging. Thus the interface moves forward and spill out of blade passage from leading edge.
\end{abstract}

\section{Introduction}

The importance of flows in the tip region for modern transonic rotors is well recognized in the gas-turbine community. Recent research results [1] suggested that nearly $1 / 3$ of the losses in rotors are contributed by the flow in the tip region. And the tip leakage flow and its interaction with the incoming main flow will be held responsible for rotating stall inception.

The interaction of shock wave and tip leakage vortex has often been pointed out as an important factor of stall inception in transonic compressors. Adamczyk[2] illustrated the flow structure in the tip region after inspecting the rollup of the tip leakage vortex, the shock wave, and the shock/vortex interaction in a transonic rotor. According to the results, the vortex breakdown produces a large number of low-energy flow clusters. Low-energy fluid comes into the rotor passage, which brings a large blockage near the rotor tip and leads to stall. Stall happens when the low-speed flow blockage spills out of the blade passage when the incoming mass flow rate decreases to the stall limit. Once stall happened, it will lead to a huge disaster. Puterbaugh and Brendel[3] further proposed a accurate two dimensional model to describe the flow-shock interaction in a transonic compressor rotor. Biella[4] demonstrated that breakdown of the tip leakage vortex is a complex question of unsteady. The unsteadiness of the flows in the tip region is mainly caused by tip leakage vortex oscillation, and the rotating disturbance induces a frequency excitation band centered around $50 \%$ blade passing frequency (BPF) at both wall and stator leading edge.

Despite many efforts, the roles that the tip leakage vortex plays in stall origination, especially in transonic compressor rotors, are still unclear and even confusing. Part of the reason is the isolation 
between experiments and computations. Different authors often give different interpretations from different perspectives based on the observed phenomena in either experiments or computations.

In this paper, the objective of the present study is to obtain fundamental knowledge of the stall inception mechanism of Rotor 37. Research objectives mainly focus on the characteristics of the tip leakage flow behavior, passage blockage, and the vertical flow structures. First, numerical analysis of NASA Rotor 37 was conducted with detailed examination of the flow field characteristics at near stall condition. Next, the typical flow features are presented and discussed. Finally, a short list of conclusions is followed.

\section{Numerical Method}

\subsection{Numerical Scheme}

The transonic axial compressor rotor, NASA Rotor 37 is adopted in the present work. The specifications of the rotor are summarized in Table 1.

Table1. Design specification of test compressor

\begin{tabular}{|c|c|}
\hline Blade number & 36 \\
\hline Design speed(rpm) & 17188.7 \\
\hline Mass flow(kg/s) & 20.19 \\
\hline Choke Mass flow(kg/s) & 20.93 \\
\hline Total pressure ration & 2.106 \\
\hline Tip speed(m/s) & 454.14 \\
\hline The inlet relative Mach at tip & 1.48 \\
\hline The inlet relative Mach at hub & 1.13 \\
\hline Solidity at tip & 1.288 \\
\hline Hub-tip ration & 0.7 \\
\hline Tip clearance $(\mathrm{mm})$ & $0.356(0.45 \%$ span $)$ \\
\hline
\end{tabular}

The software of NUMECA FINE/Turbo is used to investigate the flow details. The relatively design parameters is reported by Reid and Moore [5]. Solution technique of the three dimensional Reynolds-averaged Navier-Stokes equations are used. A cell-centered finite volume formulation is applied to discretize the model. Time integration was accomplished by the Euler implicit method with the LU-SGS scheme. The in-viscid fluxes were evaluated by the simple high-resolution upwind scheme with the third order MUSCL interpolations. The viscous fluxes were calculated in the central differential manner.

The grid of clearance is intensive. Turbulence model is S-A model. In order to, the distance of solid wall is $3 \times 10-6$ meter apart from the first layer of grid. The whole grid system had 2,480,000 cells. Distribution of grid is shown in literature [6], computational grid about rotor 37 is shown in Fig.1.

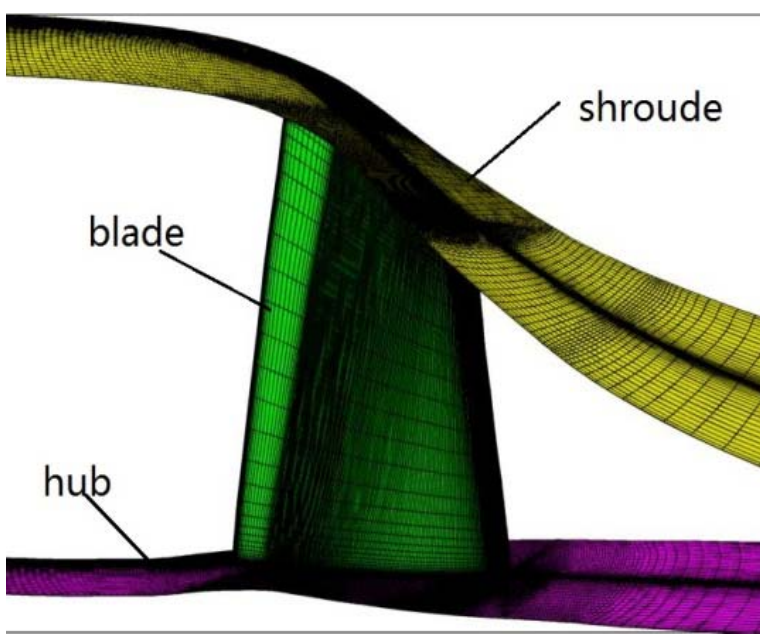

Fig.1. Computational grid about rotor 37 


\subsection{Validation.}

The computational method was validated against the experimental data of NASA Rotor 37 [7]. The overall characteristics and span-wise flow distributions are shown with the corresponding experimental data in Figs. 2 and 3, respectively. It can be seen from both figures that simulation gives a qualitatively good agreement with experimental results. There are some mismatches in tip and hub region which are thought to be caused by the overestimation of turbulence energy near casing and the absence of hub leakage flow, but on the whole, the computational method is able to predict the flow with sufficient reliability.

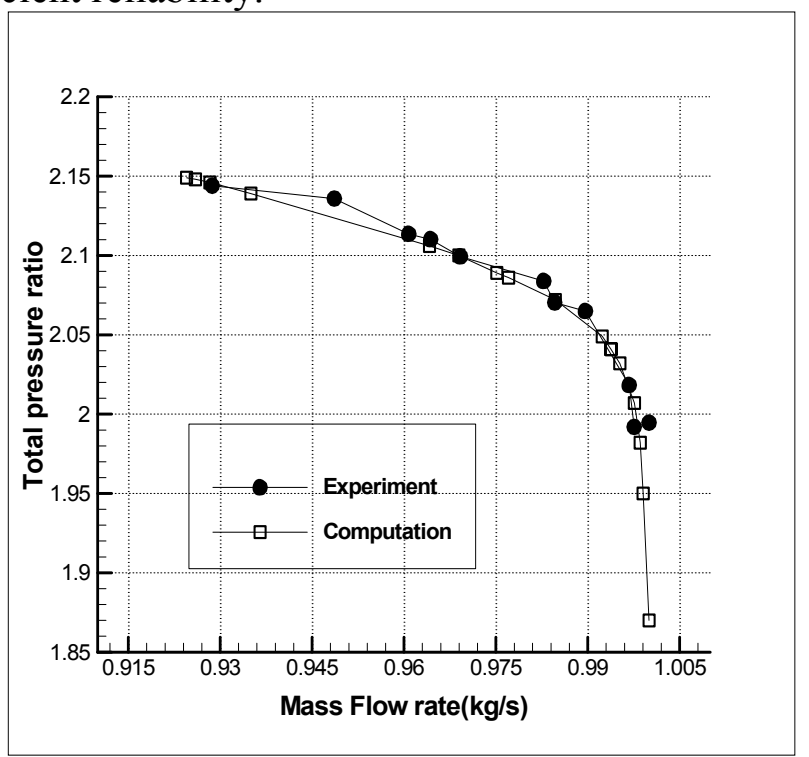

Fig. 2 Calculated and experimental total pressure ratio performance

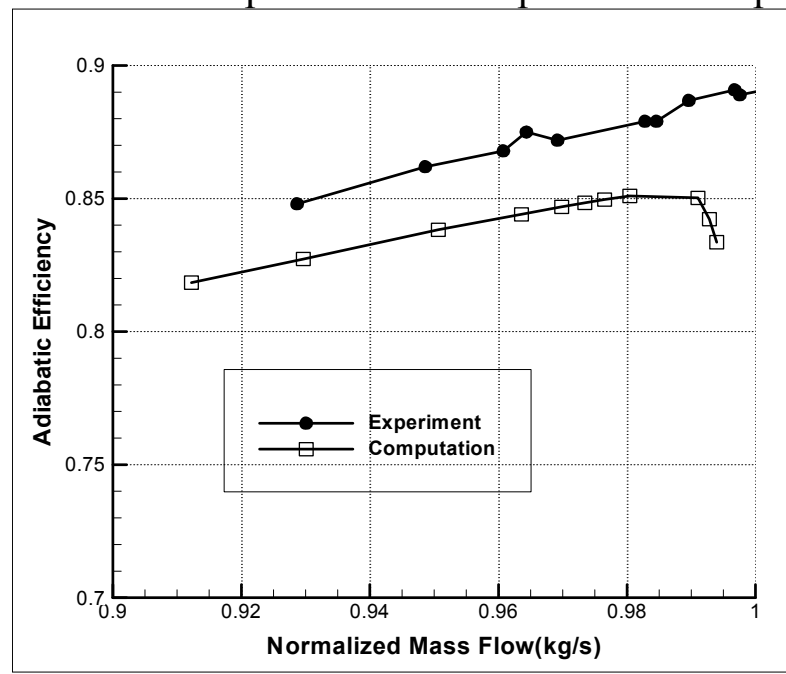

Fig. 3 Calculated and experimental adiabatic efficiency performance

\section{Results and Discussion}

The flows at the tip region are complicated by three typical flow structures: the tip clearance flow, the tip clearance flow vortex, and the shock. In this part, we will extend this model by providing simulation details in these flows. We present the two-dimensional flow structures of the tip leakage flow to observe the casing static pressure and relative Mach number contours. Then we analyze the flow structures with various visual plots to demonstrate the existence of an interface between the incoming main flow and the tip leakage flow. At last, the streamlines released at different parts along the tip chord are examined to further discover the general flow structure in the tip region.

Figure 4 shows the relative Mach number contour of 95\% span. The pictures reveal the distribution of blockage region within the blade passage. At peak efficiency (PE) operating point, 
the most dominant flow feature within the passage is the blockage widely spread on the mid-chord of suction surface. This blockage is indicating the separation of side boundary layer, caused by a strong interaction with passage shock. Other than this, any notable blockage is not found among the passage. While at near stall (NS) point, the blockage indicating the existence of tip leakage vortex expands abruptly. The blockage extends from the leading edge to the trailing edge on the pressure surface, covering wide range of the tip region. This implies that the flow which acts a dominant role in stall inception of NASA Rotor 37.

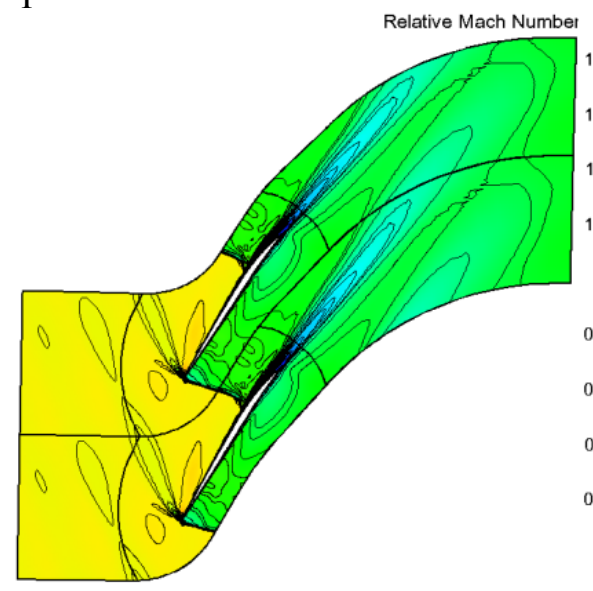

(a) Point PE

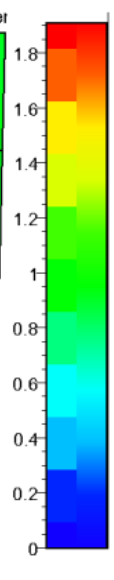

Fig.4 The relative Mach number contour of $95 \%$ span

In Fig. 5 and Fig.6, the black line symbolizes the location of the interface between the incoming flow and tip leakage flow, before which the flow is dominated by the incoming flow, yet behind which the region is mainly influenced by tip leakage flow. The blue dashed line is the location of the shock wave. The trajectory of the tip clearance vortex could be identified by the static pressure trough of the minimum pressure region. The abrupt change of static pressure can estimate the location of the shock wave. The two Figures clearly show that the incoming main flow produces the shock wave, as well as the tip leakage flow generates the tip leakage vortex.

In Fig. 5, relative total pressure contour for the operating points PE is depicted to identify the region of influence by tip leakage flows, because the relative total pressure of the region dominated by the leakage flows is much lower. Figure 5 depicts the streamlines for steady flows at point PE. The streamlines across the blade passage is considered to be over the blade cascade. From the leading edge to the mid-chord, the tip leakage flow is completely rolled into the tip leakage vortex by incoming flow. While over the last 30\% chord, the tip leakage flow is obviously more complicated.

A direct comparison between Figs. 5 and 6 can be made by visual observation. The low pressure flux cluster is actually a part of the region influenced by the tip leakage flow. The incoming main flow creates high pressure flux cluster on the pressure side when it is blocked by the strong tip leakage flow. The high pressure pushes the low pressure flux cluster to wash downstream the blade chord. It can be seen that the interface at point NS is located much closer to the leading edge than that at point PE. Meanwhile, it also can be shown that the region of influence by the tip leakage flow at point NS pierces much deeper span-wise than at point PE. According to VO's criteria [8], such an interface may cause spike-type stall inception if it spills out of the leading edge. 

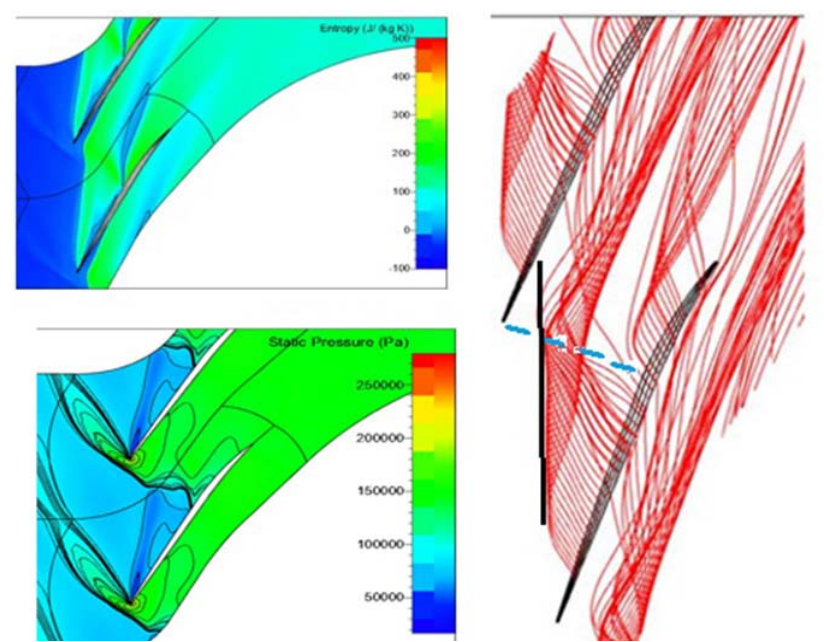

Fig.5 Illustration of the existence of the interface and the shock wave at point PE

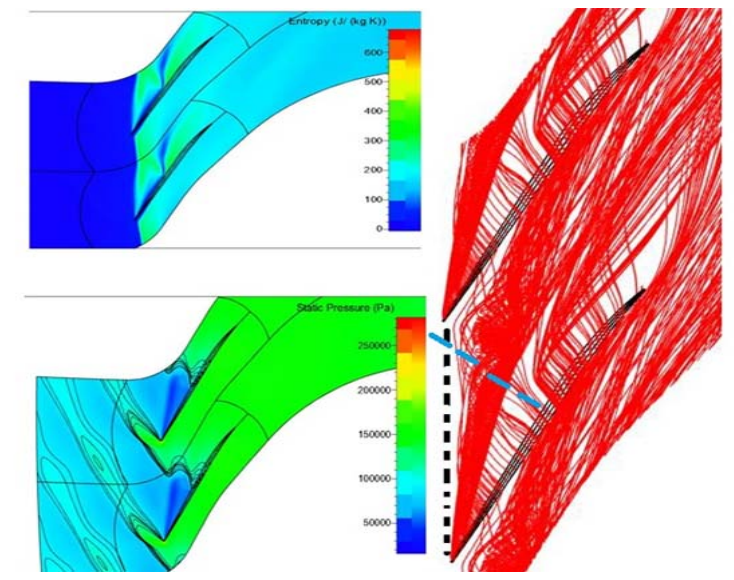

Fig.6Illustration of the existence of the interface and the shock wave at point NS

Figure 7 depicts the numerical simulations of the streamlines at the two different operations. The flow patterns for the two different operations are quite different. At operating point PE, the flows in the blade passage are divided into three parts, amount of flows in the front chord marked as (1) goes across the blade passage directly without getting evolved into the tip leakage vortex. While a small quantity of flows marked as (2) goes along the same direction as path (1) at the beginning but leaks over the rotor tip the second time and eventually rolls into the vortex in the neighboring blade passage. Just very few flows originate in the trailing edge marked as (3) flow out of the blade passage. At point PE, the tip leakage vortex maintains its structure while being drifted downstream. The corresponding blockage is negligibly small, and its position is still far away from the adjacent blade.

At operating point NS, as the mass flow is reduced, the passage shock wave advances upstream in the blade passage. The tip leakage flow passing over the leakage vortex which originates from the tip gap from the leading edge is the flow which actually contributes in deflecting the incoming flow at the interface. Meanwhile, the streamlines suddenly show a different behavior after it passes through the passage shock. The vortex expands both radically and tangentially, and drastic fluctuation appears along the vortex. These features are indicating that a tip leakage vortex breakdown has been caused by shock/vortex interaction. The vortex breakdown forms a large blockage region near the rotor tip, and the stagnating flow of the decayed vortex forms the core of the blockage. The blockage region expands abruptly along the pressure side of the adjacent blade, which enables the tip leakage flows originating from the front chord tip reach to the site near the pressure side of the leading edge. Finally, this tip clearance flow impinges to the incoming flow and cause an additional blockage region around the cracked tip leakage vortex. Consequently, this additional blockage deflects the incoming flow to increase its incidence angle. This effect interacts with the tip leakage vortex and enhances the shock/vortex interaction much more, which eventually causes the congestion of the passage in the tip region. The extent of this final process of the stall 
inception is limited near the tip region and would initiate the spike type rotating stall.

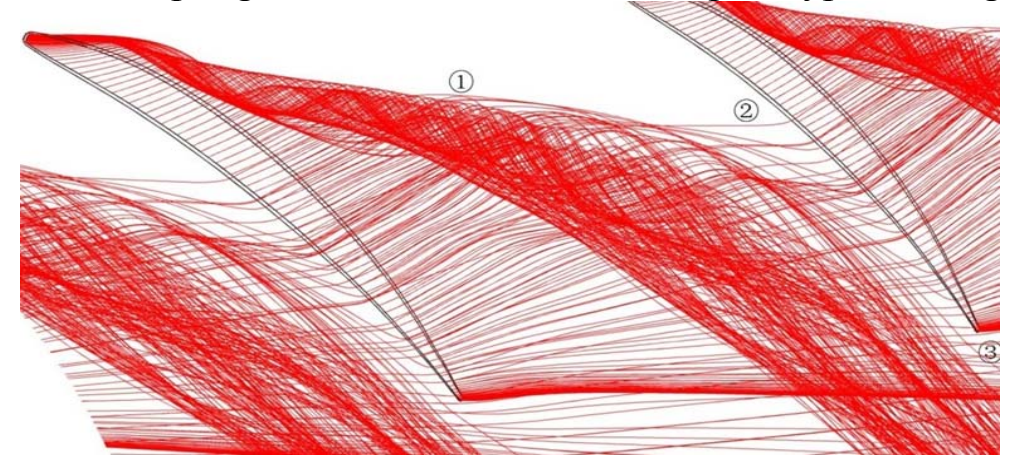

(a) Point PE

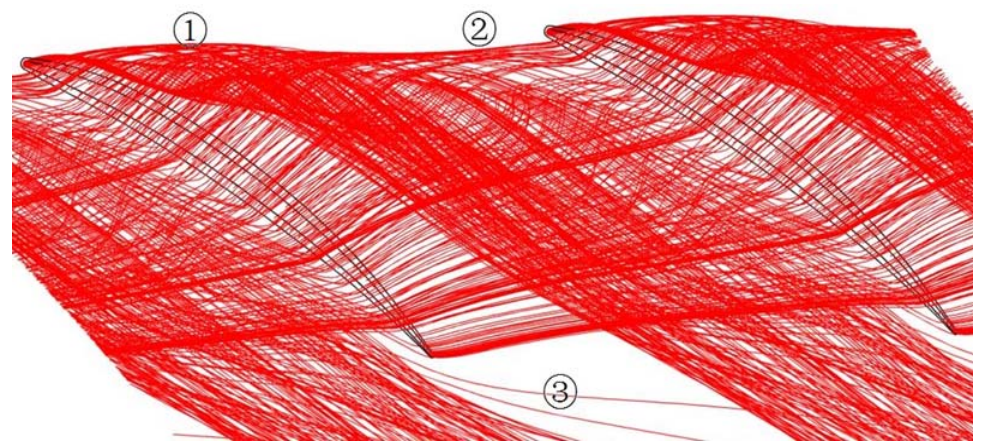

(b) Point NS

Fig.7 The streamlines released in tip region.

However, through the above analysis, the author would like to stand in a more macro $\mathrm{p}$ erspective to explore the mechanism of the stall. When flow and tip leakage flow intersect with each other, there is great rivalry between the two flows. If the power of incoming flo $\mathrm{w}$ is relatively large, the flow will be coerced a lot of tip clearance leakage flow smoothly

into the passage. And vortex breakdown would not have happened to produce large numbe rs of low-energy groups. And after the "collision" of the incoming flow, the secondary tip clearance flow will be greatly reduced. The efficiency of compressor will rise. Conversely, i $\mathrm{f}$ the power of incoming flow is relatively small, tip part of the clearance leakage flow wil 1 be enveloped into the blade passage by main flow. But this part is unable to be taken ou $\mathrm{t}$ of the blade passage, and the collision of the two weakens their respective power further more. Under the influence of reverse pressure gradient, the vortex breakdown and low ener gy mass blockage escalate. As a result of the gradually decreasing power of the incoming $f$ low, the secondary tip clearance flow get emerging. Thus the interface moves forward and spill out of blade passage from leading edge.

\section{Conclusions}

In this paper the flow structures in the tip region of a transonic rotor are investigated numerically. The two major discoveries are summarized in details as below:

(1) The tip leakage flow along the blade chord can be divided into at least three parts. The first portion of the tip leakage flow goes across the blade passage directly without getting evolved into the tip leakage vortex and impinges the neighboring blade's pressure side. The second part interacts with the main flow and rolls up into a tip leakage vortex. The very few flows originating in the trailing edge flow out of the blade passage. The vortex core may be enlarged once it interacts with the shock shave.

(2) In NASA Rotor 37, a distinctive breakdown of tip leakage vortex is seen in near-stall condition. The low-speed flows caused by the vortex breakdown acts as blockages near the tip region. Many blockages in the tip region enable the tip leakage flow to impinge deeply toward the pressure side of the adjacent blade. This flow generates blockage near the leading edge once again, which enhances the spillage to occur. 
(3) When flow and tip leakage flow intersect with each other, there is great rivalry between the two flows. If the power of incoming flow is relatively large, the flow will be coerced a lot of tip clearance leakage flow smoothly into the passage. And vortex breakdown would not have happened to produce large numbers of low-energy groups. And after the "collision" of the incoming flow, the secondary tip clearance flow will be greatly reduced. The efficiency of compressor will rise. Conversely, if the power of incoming flow is relatively small, tip part of the clearance leakage flow will be enveloped into the blade passage by main flow. But this part is unable to be taken out of the blade passage, and the collision of the two weakens their respective power further more. Under the influence of reverse pressure gradient, the vortex breakdown and low energy mass blockage escalate. As a result of the gradually decreasing power of the incoming flow, the secondary tip clearance flow get emerging. Thus the interface moves forward and spill out of blade passage from leading edge.

\section{References}

[1] Denton, J. D., 1993, "Loss Mechanisms in Turbomachines," ASME J. Turbomach.,115, pp. 621-656. [2] Adamczyk, J. J., Celestina, M. L., and Greitzer, E. M., 1993, "The Role of Tip Clearance in High-Speed Fan Stall,” ASME J. Turbomach., 115, pp. 28-39.

[3] Bergner, J., and Hennecke, D. K., 2003, "Experimental Study of Stall Inception of a Single-Stage Transonic Compressor," Proceedings of the 16th Symposium Air Breathing Engines, Cleveland, OH, August 31-September 5, Paper No.ISABE-2003-1081.

[4] Biela, C., Muller, M. W., Schiffer, H., and Zscherp, C., 2008, "Unsteady Pressure Measurement in a Single Stage Axial Transonic Compressor Near the Stability Limit," ASME Paper No. GT2008-50245.

[5] Reid, L.and Moore, R. D., 1978. Design and overall performance of four highly-loaded, high-speed inlet stages for an advanced, high-pressure-ratio core compressor[R]. NASA.TP-1337.

[6]XIE Fang, CHU Wu-li, ZHANG Hao-guan, Influence shock waves leakage vortex boundary layer separation interaction in a single- stage transonic axial compressor[J] , 2012.27(2),425-430.

[7] Suder, K. L., and Celestina, M. L., 1996, "Experimental and Computational Investigation of the Tip Clearance Flow in a Transonic Axial Compressor Rotor," ASME J. Turbomach., 118(2), pp. $218-229$.

[8] Vo, H. D., Tan, C. S., and Greitzer, E. M., 2008, “Criteria for Spike Initiated Stall,” ASME J. Turbomach., 130(1), p. 011023. 